\title{
Multidimensional assessment of the effects of erenumab in chronic migraine patients with previous unsuccessful preventive treatments: a comprehensive real-world experience
}

\author{
Antonio Russo ${ }^{1 *+}$ (D), Marcello Silvestro ${ }^{1 \dagger}$, Fabrizio Scotto di Clemente ${ }^{1}$, Francesca Trojsi , Alvino Bisecco ${ }^{1}$,
} Simona Bonavita ${ }^{1}$, Alessandro Tessitore ${ }^{1}$ and Gioacchino Tedeschi ${ }^{1,2}$

\begin{abstract}
Background: erenumab was safe and effective in clinical trials for the prevention of migraine. However, real-life data are still lacking. Here we report the clinical experience from an Italian real-world setting using erenumab in patients with chronic migraine experiencing previous unsuccessful preventive treatments.

Methods: Seventy patients with chronic migraine and failure to $\geq 4$ migraine preventive medication classes initially received monthly erenumab $70 \mathrm{mg}$ s.c. Patients without a clinically meaningful improvement, considered as a $>30 \%$ reduction in headache days per month, after $\geq 3$ months of therapy switched to monthly erenumab $140 \mathrm{mg}$. At the first administration and after 3 and 6 months, patients underwent extensive interviews to assess clinical parameters of disease severity and migraine-related disability and impact, and validated questionnaires to explore depression/ anxiety, sleep, and quality of life (QoL). Finally, the Pain Catastrophizing Scale, Allodynia Symptom Checklist-12 and MIGraine attacks-Subjective COGnitive impairments scale (MIG-SCOG) were administered.
\end{abstract}

Results: $70 \%$ of patients were "responders" after the third administration of erenumab $70 \mathrm{mg}$, whereas 30\% switched to erenumab $140 \mathrm{mg}$; 29\% (6 pts) responded after the sixth administration. The headache-day frequency was reduced from $21.1 \pm 0.7$ to $11.4 \pm 0.9$ days after the third administration $(p<0.001)$ and to $8.9 \pm 0.7$ days after the sixth administration ( $p<0.001$ ). $53 \%$ and $70 \%$ of patients, respectively, showed a reduction of $\geq 50 \%$ of headache days/month after the third and the sixth administrations.

Also improved were headache pain severity, migraine-related disability, and impact on daily living, QoL, pain catastrophizing and allodynia (all $p<0.001$ ), quality of sleep, symptoms of depression or anxiety $(p<0.05)$ but not MIG-SCOG. There were no new adverse event signals.

(Continued on next page)

\footnotetext{
*Correspondence: dottor.russo@gmail.com

${ }^{\dagger}$ Antonio Russo and Marcello Silvestro contributed equally to this work. 'Department of Medical, Surgical, Neurological, Metabolic and Aging Sciences, Headache Center, University of Campania "Luigi Vanvitelli", Piazza Miraglia $2-1,80138$ Naples, Italy

Full list of author information is available at the end of the article
}

C C The Author(s). 2020 Open Access This article is licensed under a Creative Commons Attribution 4.0 International License, which permits use, sharing, adaptation, distribution and reproduction in any medium or format, as long as you give appropriate credit to the original author(s) and the source, provide a link to the Creative Commons licence, and indicate if changes were made. The images or other third party material in this article are included in the article's Creative Commons licence, unless indicated otherwise in a credit line to the material. If material is not included in the article's Creative Commons licence and your intended use is not permitted by statutory regulation or exceeds the permitted use, you will need to obtain permission directly from the copyright holder. To view a copy of this licence, visit http://creativecommons.org/licenses/by/4.0/. The Creative Commons Public Domain Dedication waiver (http://creativecommons.org/publicdomain/zero/1.0/) applies to the data made available in this article, unless otherwise stated in a credit line to the data. 
(Continued from previous page)

Conclusion: These real-world data support monthly erenumab 70 or $140 \mathrm{mg}$ s.c. as a safe and effective preventive treatment to reduce headache frequency and severity in chronic migraine patients experiencing previous unsuccessful preventive treatments.

Keywords: Chronic migraine, Erenumab, Migraine, Monoclonal antibodies, Real-world

\section{Background}

The International Classification of Headache Disorders stratifies migraine into episodic or chronic, when patients experience less than or more than 15 days, respectively, of headache per month for at least 3 months, with the migraine features present at least eight days per month [1].

It is of note that chronic migraine, accompanied by functional and microstructural brain abnormalities [2], is associated with a substantially greater personal and societal burden and higher frequency of comorbidities [3]. Nevertheless, although strongly recommended as a crucial component of migraine management, only a minority of patients with chronic migraine $(40 \%)$ follow preventive therapies and fewer than $25 \%$ adhere to preventive medications 1 year after initiating treatment [4], due to low efficacy, side effects or both $[3,5]$. Therefore, the standard preventive care based on repositioning drugs discovered by "serendipity" still seems to be a challenging issue, particularly with regard to the therapeutic approach to chronic migraine, for which Onabotulinumtoxin type A (onabotulinumtoxin A) is the only guidelineslicensed treatment is [6].

In this context, monoclonal antibodies (mAbs) targeting the calcitonin gene-related peptide (CGRP) or its receptor represent the first selective therapeutic approach specific for migraine prevention [7-12].

Four CGRP antagonists have been developed, undergone experimental testing, and finally been approved as the first selective therapies specifically for migraine prevention: eptinezumab (ALD 403), fremanezumab (TEV49125), galcanezumab (LY29517542) and erenumab (AMG 334) [7-9]. Eptinezumab, fremanezumab, and galcanezumab bind to the CGRP molecule, whereas erenumab binds to the CGRP receptor [7, 8, 12-14]. Erenumab $[15,16]$ is a fully human monoclonal antibody shown to be effective and well-tolerated in the preventive therapy of episodic and chronic migraine, with and without medication overuse, even when previous preventive approaches have failed [17].

Recent real-life data from observational studies confirmed that erenumab is highly effective and welltolerated for the treatment of patients with highfrequency episodic migraine or chronic migraine [1820]. On the other hand, although the effectiveness of erenumab has been documented in episodic migraine patients with failure of previous preventive treatments and in chronic migraine patients, regardless of previous therapeutic strategies, limited data have been explicitly produced regarding its efficacy in chronic migraine patients who have failed several preventive medication classes [21, 22], which probably represents the most difficult scenario to deal with in clinical practice.

Furthermore, although previous experimental trials showed the safety and effectiveness of erenumab therapy, similar real-life data are still lacking, as well as evidence for its impact on different aspects of the lives of patients.

Herein, we report the clinical experience from an Italian real-world setting using erenumab in a cohort of chronic migraine patients experiencing previous unsuccessful treatments with anti-migraine preventive therapies.

\section{Methods}

\section{Study design and participants}

This was an observational, prospective, non-randomized, open-label study evaluating the efficacy and safety of erenumab in the treatment of chronic migraine patients with failure of previous preventive treatments. Seventy patients with chronic migraine (according to the International Headache Society criteria [1]) were consecutively recruited from the migraine population being referred to the Headache Center of the Department of Neurology at the University of Campania "Luigi Vanvitelli" between February 2019 and July 2019 and followed up for 6 months. We included only chronic migraine patients aged between 18 and 65 years who had received and failed at least four or more oral preventive medication classes (propranolol or metoprolol, topiramate, flunarizine, valproate, amitriptyline, or candesartan) or onabotulinumtoxinA due to lack of efficacy or intolerable side effects. Guided by the exclusion criteria of the available trials and previous real-life studies, migraine patients with concomitant well-defined psychiatric disorders (psychosis, bipolar disorders, or severe depressive symptoms) were excluded from enrolment. The baseline headache frequency (defined as the monthly mean of headaches during the 3 months preceding erenumab treatment) as well as the headache frequency during erenumab treatment were evaluated by reviewing standardized paper patient headache diaries. 
Efficacy failure was defined as no meaningful improvement $(<30 \%$ of reduction in headache days/month) in the frequency of headaches after the administration of drugs for at least 3 months, as recommended by the European Headache Federation treatment guidelines [23]. Tolerability failure was defined as documented discontinuation due to adverse events at any previous time.

Patients were allowed to take other preventive oral (alone or in combination) or injected therapies if the dose had been stable for at least 3 months before starting treatment with erenumab and remained stable for the entire duration of erenumab treatment.

All patients received monthly erenumab $70 \mathrm{mg}$ subcutaneous (s.c.) until the third administration. Then, patients with a clinically meaningful improvement $(\geq 30 \%$ reduction of migraine days per month) [24] continued with the unchanged dose, whereas patients with no clinically meaningful improvement $(<30 \%$ reduction of headache days per month) continued with monthly erenumab $140 \mathrm{mg}$ s.c.

At the first administration $\left(\mathrm{T}^{0}\right)$, at the end of the third $\left(\mathrm{T}^{1}\right)$ and of the sixth month $\left(\mathrm{T}^{2}\right)$ of erenumab treatment, all patients underwent an extensive interview aimed at assessing clinical parameters of disease severity such as headache days per month, pain intensity (assessed by numerical rating scale [NRS]), acute pain medication intake and migraine-related disability (by MIDAS) $[25,26]$ and impact by Headache Impact Test (HIT-6) [27-29]. Furthermore, patients underwent questionnaires aimed at exploring a) comorbid depression and anxiety by the Beck Depression Inventory-II (BDI-II), Hamilton Depression Rating Scale (HDRS) [30], Hamilton Anxiety Rating Scale (HARS) [31]; b) quality of sleep by the Medical Outcomes Study (MOS) Sleep Scale [32] c) quality of life by the migraine-specific quality-of-life questionnaire (MSQ) [33, 34]. Finally, Pain Catastrophizing Scale (PCS) [35], Allodynia Symptom Checklist-12 (ASC-12) [36], and MIGraine attacks - Subjective COGnitive impairments scale (MIG-SCOG) [37] were administered. During the 6 months period of observation, all adverse events (AEs) related to the drug were recorded and used as a safety measure.

The protocol was reviewed and approved by the Ethical Committee of the University of Campania "Luigi Vanvitelli". Each patient gave a free, informed consent for participation in the study and the analysis and publication of the protocol data. The study was done according to the Strengthening the Reporting of Observational Studies in Epidemiology (STROBE) guidelines [38].

\section{Outcomes}

The primary endpoint was the proportion of patients who achieved at least 30\%, 50\% and 75\% reduction from their individual baseline in monthly headache days at the end of the third $\left(\mathrm{T}^{1}\right)$ and of the sixth month $\left(\mathrm{T}^{2}\right)$ of erenumab treatment. Secondary efficacy endpoints were the change from baseline in monthly headache days, pain intensity, monthly acute migraine medication intake days, and change from baseline in HIT-6, MIDAS, BDI-II, HDRS, HARS, MOS sleep scale, MSQ, ASC-12, MIGSCOG and PCS scores at the end of the third $\left(\mathrm{T}^{1}\right)$ and of the sixth month $\left(\mathrm{T}^{2}\right)$ of erenumab treatment.

The following secondary endpoints were also assessed: a) percentage of patients converting from medication overuse to non-medication overuse after the third and the sixth monthly erenumab administrations, b) temporal patterns of response to erenumab (e.g., percentage of patients responding in the first month of treatment), c) sustained response to erenumab (e.g., percentage of patients getting a response in the first month and maintaining it in the following 5 months) and d) percentage of non-responder patients at 3 months obtaining a response after a dose increase to $140 \mathrm{mg} / \mathrm{month}$. Finally, a sub-analysis was conducted in those patients previously treated with onabotulinumtoxinA injections.

Safety and tolerability were assessed by recording observed or reported adverse events and by physical examination.

\section{Statistical analysis}

Continuous variables are reported as mean \pm standard error (SE), rates and categorical values are reported as subjects-counts and percentage. In the population treated with erenumab, the paired t-test was used to compare the mean headache days, pain intensity, medication intake per month, HIT-6, MIDAS, BDI-II, HDRS, HARS, MOS sleep scale, MSQ, ASC-12, MIG-SCOG and PCS scores at baseline $\left(\mathrm{T}^{0}\right)$ and at the end of the third $\left(\mathrm{T}^{1}\right)$ and of the sixth month $\left(\mathrm{T}^{2}\right)$ of erenumab treatment. Multivariate regression analysis was conducted, including several demographic data (sex, age, migraine onset), and parameters of disease severity (attack frequency, pain intensity, disease duration, MIDAS, HIT-6, ASC-12, PCS scores) to determine the independent predictors of response to erenumab treatment. All analyses were performed using STATA version 14 (StataCorp, College Station, TX, USA).

\section{Results}

\section{Demographic and baseline headache characteristics}

The whole population consisted of 70 patients. The majority of patients were female $(78.6 \%)$, with a mean age of $46.9 \pm 1.4$ years (range 18-75). The average time since onset of migraine was $33.1( \pm 1.2)$ years. Demographic and baseline headache characteristics of patients included in the study are reported in Table 1 . All patients had experienced multiple failures of preventive treatment, sometimes leading to treatment discontinuation, 
Table 1 Baseline demographic and clinical parameters

\begin{tabular}{ll}
\hline Characteristics & $N=70$ \\
\hline Age & $46.9 \pm 1.4$ \\
Gender & \\
$\quad$ Male & $15(21.4)$ \\
$\quad$ Female & $55(78.6)$ \\
Age at migraine onset, years & $14.1 \pm 0.9$ \\
Disease duration, years & $33.1 \pm 1.2$ \\
Concurrent oral preventive treatments & $40(57)$ \\
$\quad$ Monotherapy & $18(26)$ \\
$\quad$ Polytherapy & $22(31)$ \\
Headache days/month & $21.1 \pm 0.7$ \\
Previous preventive classes failure & $4.7 \pm 0.3$ \\
Acute medications intake/month & $25 \pm 3.7$ \\
Patients with MOH & $64(91.4)$ \\
Pain intensity (NRS) & $8.6 \pm 0.6$ \\
MIDAS & $108.1 \pm 11.4$ \\
HIT-6 & $65.9 \pm 1.2$ \\
MSQ & $13.2 \pm 7.5$ \\
BDI-II & $17.0 \pm 1.5$ \\
HDRS & $14.3 \pm 1.2$ \\
MARS & $17.1 \pm 1.7$ \\
ASC-12 & $24.7 \pm 0.7$ \\
PCS & $6.7 \pm 0.7$ \\
MIG-SCOG & $33.2 \pm 1.3$ \\
Vateep scale & $9.9 \pm 0.6$ \\
\hline
\end{tabular}

Values are mean \pm standard error (SE) or number (\%)

ASC-12 Allodynia Symptom Checklist-12, BDI II Beck Depression Inventory II, HARS Hamilton Anxiety Rating Scale, HDRS Hamilton Depression Rating Scale, HIT-6 headache impact test-6, MIDAS migraine disability assessment scale, MIGSCOG MIGraine attacks - Subjective COGnitive impairments scale, $\mathrm{MOH}$ medication overuse headache, MOS Medical Outcomes Study, MSQ migrainespecific quality-of-life questionnaire, NRS numerical rating scale, PCS Pain Catastrophizing Scale due to no meaningful improvement $(<30 \%$ reduction in headache days per month) or adverse events (Table 2).

\section{Primary efficacy endpoint}

Figure 1 shows the percentage of responders at the end of the third $\left(\mathrm{T}^{1}\right)$ and of the sixth month $\left(\mathrm{T}^{2}\right)$ of erenumab administration. After the third administration of monthly erenumab $70 \mathrm{mg}$ s.c., $70 \%(n=49)$ of patients were considered "responders" (e.g., $\geq 30 \%$ reduction of headache days/month) and continued with monthly erenumab $70 \mathrm{mg}$ s.c., whereas the remaining 30\% (21 pts) were considered "non-responders" (e.g., < $30 \%$ reduction of headache days/month) and therefore switched to monthly erenumab $140 \mathrm{mg}$ s.c. Among the latter, 29\% (6 pts) were considered "responders" after the subsequent three administrations of monthly erenumab $140 \mathrm{mg}$ s.c.

After the third administration of monthly erenumab $70 \mathrm{mg}$ s.c. $53 \%$ ( $37 \mathrm{pts}$ ) and $18 \%$ (13 pts) of patients reported respectively $\mathrm{a} \geq 50 \%$ or $\mathrm{a} \geq 75 \%$ reduction in headache days per month.

After the sixth administration of monthly erenumab (70 mg s.c. or $140 \mathrm{mg}$ s.c.) $70 \%$ (49 pts) and 26\% (18 pts) of patients reported respectively $\mathrm{a} \geq 50 \%$ or $\mathrm{a} \geq 75 \%$ reduction in the monthly number of headache days when compared to baseline.

\section{Secondary efficacy endpoints}

Statistically significant improvements were observed after the third erenumab $70 \mathrm{mg}$ s.c. administration and then confirmed after the sixth administration $(70 \mathrm{mg}$ s.c. or $140 \mathrm{mg} \mathrm{s.c.)}$ in the following secondary endpoints (Table 3).

Headache-day frequency decreased from a baseline mean of $21.1 \pm 0.7$ to $11.4 \pm 0.9$ days after the third administration $(p<0.001)$ and to $8.9 \pm 0.7$ days after the sixth administration $(p<0.001)$ (Fig. 2). Significant improvements compared with baseline were seen in headache pain severity scores assessed by NRS $(p<0.001)$, migraine-related disability assessed by MIDAS and HIT$6(p<0.001)$ and impact on daily living assessed by

Table 2 Prior anti-migraine preventive therapies of patients $(N=70)$ in the study, showing pharmacological classes and corresponding reason for failure

\begin{tabular}{lllll}
\hline & Patients & No meaningful improvement & Adverse events & Treatment discontinuation $^{a}$ \\
\hline Tricyclic antidepressants & $65(93)$ & $55(85)$ & $10(15)$ & $48(68)$ \\
Beta-blockers & $63(90)$ & $56(88)$ & $7(12)$ & $48(68)$ \\
Calcium channel blockers & $28(40)$ & $22(78)$ & $6(12)$ & $25(36)$ \\
Topiramate & $62(88)$ & $47(76)$ & $15(24)$ & $50(71)$ \\
Valproate & $15(21)$ & $9(60)$ & - & $13(18)$ \\
OnabotulinumtoxinA & $54(77)$ & $54(100)$ & & $49(70)$ \\
\hline
\end{tabular}

Values are no. (\%)

${ }^{a}$ Due to no meaningful improvement or adverse event 


\section{Percentage of responders}

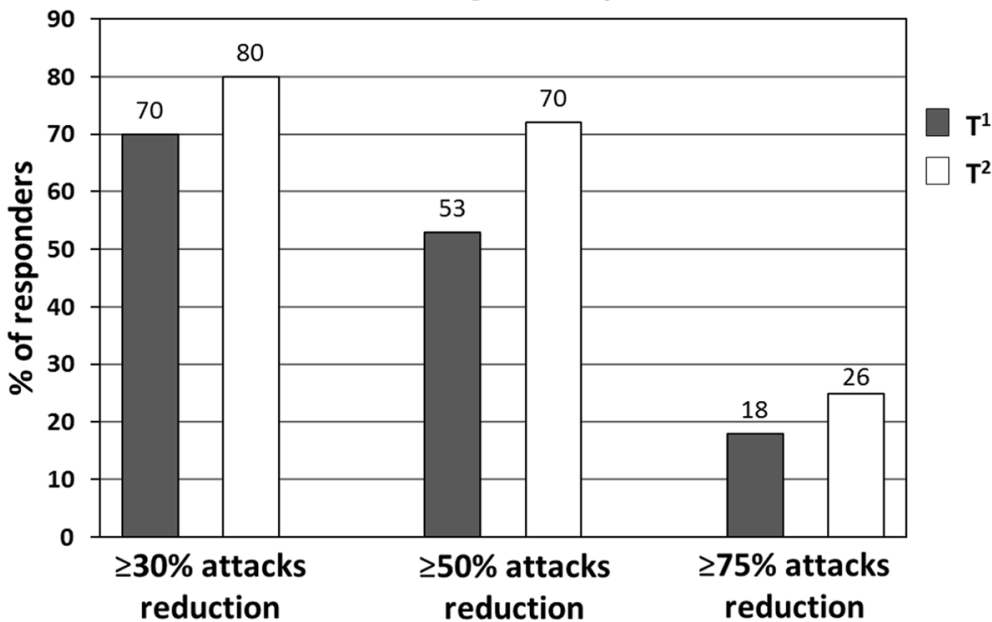

Fig. 1 Primary outcome: Percentage of responders at the end of the third $\left(T^{1}\right)$ and of the sixth month $\left(T^{2}\right)$ of erenumab administration

MSQ $(p<0.001)$ after the third and sixth administration (Fig. 3).

Depression and anxiety assessed by BDI-II, HDRS and HARS $(p<0.05)$ significantly improved from baseline after the sixth administration (Fig. $4 \mathrm{a}-\mathrm{c}$ ), and most measures of pain catastrophizing significantly reduced after the third administration and were maintained throughout treatment $(p<0.0001)$ (Fig. $4 \mathrm{~d})$.

Allodynia symptoms assessed by ASC-12 significantly improved after the third and sixth administration $(p<0.001)$ (Fig. 5), and quality of sleep assessed by the MOS sleep scale significantly

Table 3 Efficacy endpoints after the third and sixth monthly erenumab administrations $(n=70)$

\begin{tabular}{|c|c|c|c|}
\hline \multirow[t]{2}{*}{ Outcomes } & \multirow[t]{2}{*}{ Baseline } & \multicolumn{2}{|c|}{ Administration } \\
\hline & & Third & Sixth \\
\hline \multicolumn{4}{|l|}{ Reduction from baseline in MHD } \\
\hline$\geq 30 \%$ & & $49(70)$ & $56(80)$ \\
\hline$\geq 50 \%$ & & $37(53)$ & $49(70)$ \\
\hline$\geq 75 \%$ & & $13(18)$ & $18(26)$ \\
\hline Response after dose increase in non-responder patients & - & - & $6 / 21(29)$ \\
\hline $\mathrm{MHD}$ & $21.1 \pm 0.7$ & $11.4 \pm 0.9^{*}$ & $8.9 \pm 0.7^{*}$ \\
\hline Conversion from chronic to episodic migraine & - & $46(66)$ & $49(70)$ \\
\hline Conversion from medication overuse to non-overuse & - & $40(57)$ & $43(62)$ \\
\hline Pain intensity (NRS) & $8.6 \pm 0.1$ & $8.1 \pm 0.1^{*}$ & $7.9 \pm 0.1^{*}$ \\
\hline MIDAS & $108.1 \pm 11.2$ & $54.5 \pm 11.4^{*}$ & $51.0 \pm 9.7^{*}$ \\
\hline HIT-6 & $65.9 \pm 1.2$ & $60.7 \pm 1.2^{*}$ & $59.5 \pm 1.4^{*}$ \\
\hline MSQ & $62.7 \pm 7.5$ & $42.0 \pm 7.6^{*}$ & $41.5 \pm 7.7^{*}$ \\
\hline BDI-II & $17.0 \pm 1.4$ & $13.2 \pm 1.5$ & $11.2 \pm 1.6^{*}$ \\
\hline HDRS & $14.3 \pm 0.9$ & $12.3 \pm 1.5$ & $10.5 \pm 1.2^{*}$ \\
\hline HARS & $17.1 \pm 1.2$ & $15.1 \pm 1.7$ & $13.2 \pm 1.6^{*}$ \\
\hline PCS & $33.2 \pm 1.3$ & $24.9 \pm 1.8^{*}$ & $25.8 \pm 2.1^{*}$ \\
\hline MOS Sleep Scale & $24.7 \pm 0.7$ & $24.2 \pm 0.8$ & $22.9 \pm 1.1^{*}$ \\
\hline ASC-12 & $6.7 \pm 0.7$ & $5.5 \pm 0.8^{*}$ & $4.8 \pm 0.8^{*}$ \\
\hline MIG-SCOG & $9.9 \pm 0.6$ & $8.6 \pm 0.6$ & $8.8 \pm 0.8$ \\
\hline
\end{tabular}

Values are mean \pm standard error (SE) or number (\%)

* statistically significant difference (in comparison with baseline)

ASC-12 Allodynia Symptom Checklist-12, BDI II Beck Depression Inventory II, HARS, Hamilton Anxiety Rating Scale, HDRS Hamilton Depression Rating Scale, HIT-6 headache impact test- 6, MIDAS migraine disability assessment scale, MIG-SCOG MIGraine attacks - Subjective COGnitive impairments scale, MHD monthly headache days, $M O H$ medication overuse headache, MOS Medical Outcomes Study, MSQ migraine-specific quality-of-life questionnaire, NRS numerical rating scale, PCS Pain Catastrophizing Scale 


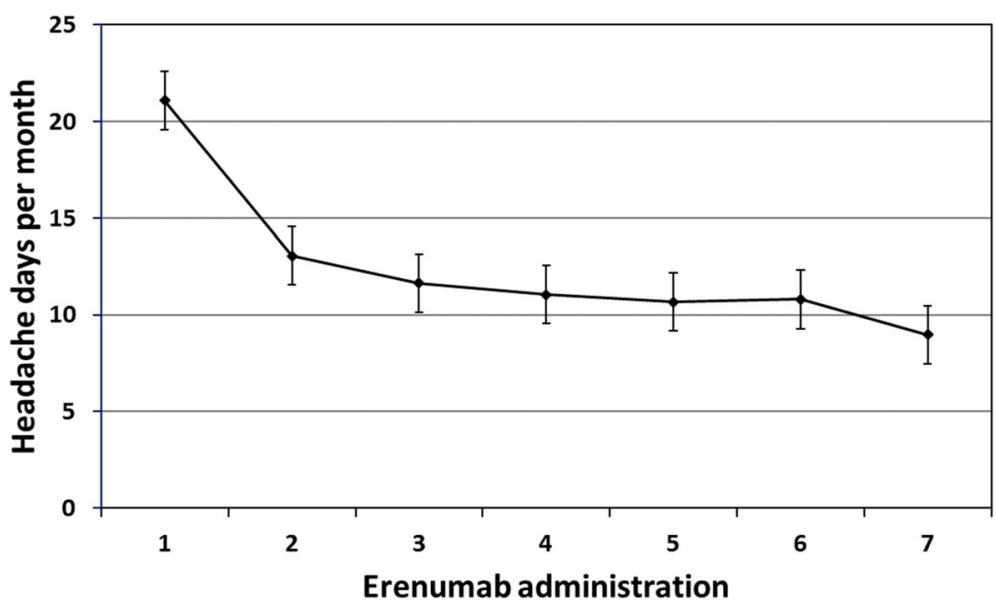

Fig. 2 Change in headache-day frequency after each erenumab administration

improved from baseline after the sixth administration $(p<0.05)$ (Fig. 5B).

Subjective cognitive impairment experienced during migraine attacks assessed by MIG-SCOG did not show statistically significant improvement after either the third or sixth administrations.

In the whole cohort of 70 patients, $60 \% \quad(n=42)$ showed $a \geq 30 \%$ reduction in headache days in the thirty days following the first erenumab administration.

Among the 49 patients considered "responders" after the third administration of monthly erenumab $70 \mathrm{mg}$ s.c, a sustained response after the sixth erenumab administration was observed in $92 \%$. Furthermore, 57\% and 62\% of patients converted from medication overuse to nonmedication overuse after the third and the sixth erenumab administration.

Secondary analysis conducted on 54 patients with a previous failure of onabotulinumtoxinA reported in 56\% (30 pts) $\mathrm{a} \geq 30 \%$ reduction in headache days per month after the sixth erenumab administration.

Analysis of odds ratio (OR) of the multivariate regression analysis found disease duration as a statistically significant negative prognostic factor of response to erenumab treatment (OR: 0.36, $p<0.005$ ) (e.g., the shorter the disease duration, the better the erenumab treatment response).

\section{Safety and tolerability}

Treatment-related AEs were consistent with the wellknown tolerability profile of erenumab [39]. Overall, $25.7 \%$ of patients reported an AE: constipation (23.9\%), fatigue (7\%), and nausea (5\%) were the most frequently reported in the course of treatment. There were no serious AEs, and no patient discontinued treatment due to adverse events.

\section{Discussion}

Chronic migraine imposes a considerable negative burden that affects many important aspects of life, including marital, parenting, romantic and family relationships, career/financial achievement and stability, and overall health [40], and is recognized as the second-highest cause of years lived with disability, and the first in patients aged between 15 and 49 years [41]. Hence, there is a significant unmet need for effective therapies that address the current limited preventive therapeutic options, characterized by frequent unsatisfactory responses, side effects and a consequent poor adherence of patients $[3,42]$.

The availability of CGRP mABs as novel, welltolerated, specific, and effective therapeutic options, represents an important advance in the management of migraine prevention [43, 44]. Among CGRP mABS, evidence for the efficacy and safety of erenumab in migraine prevention has been provided from rigorously controlled, randomized, double-blind, placebo-controlled, phase 2 or 3 b studies [39, 45-48].

More specifically, a phase 2 study conducted in a cohort of chronic migraine patients showed a reduction of monthly migraine days of 6.6 as compared with 4.2 days in the placebo group [49].

The ARISE study, conducted in episodic migraine patients, showed a reduction of 2.9 days in monthly migraine days, compared with -1.8 days for placebo and a $50 \%$ or greater reduction from baseline in monthly migraine days in the $39.7 \%$ of patients treated with monthly erenumab administration compared with $29.5 \%$ of the placebo group [50]. Similarly, the STRIVE study showed in a cohort of episodic migraine patients a decrease in monthly migraine days of 3.2 in the $70-\mathrm{mg}$ erenumab group and 3.7 in the $140-\mathrm{mg}$ erenumab group, versus 1.8 days with placebo [51]. Furthermore, $a \geq 50 \%$ 


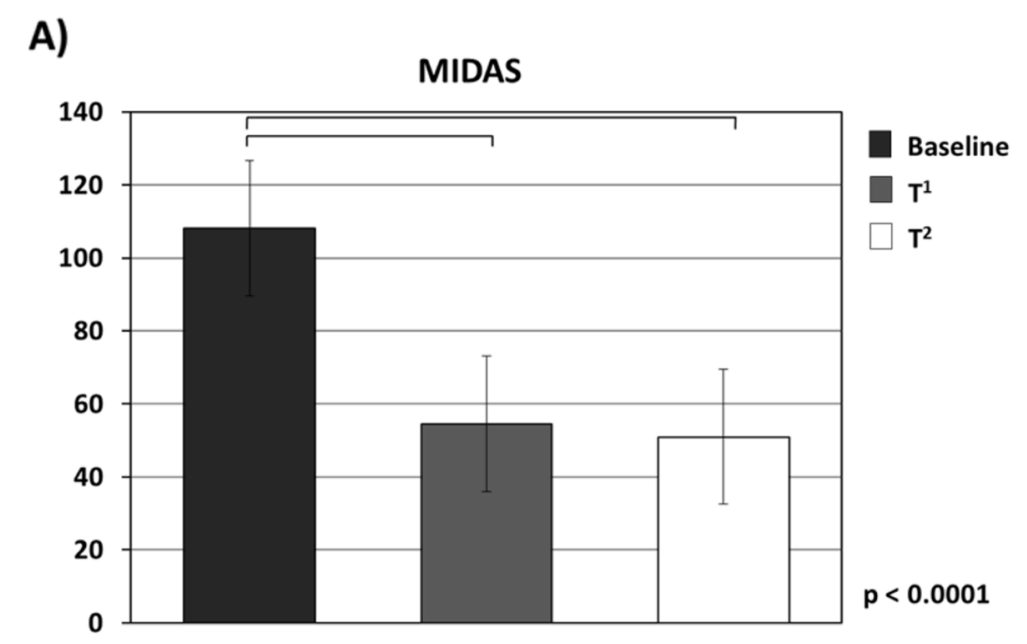

B)

HIT-6

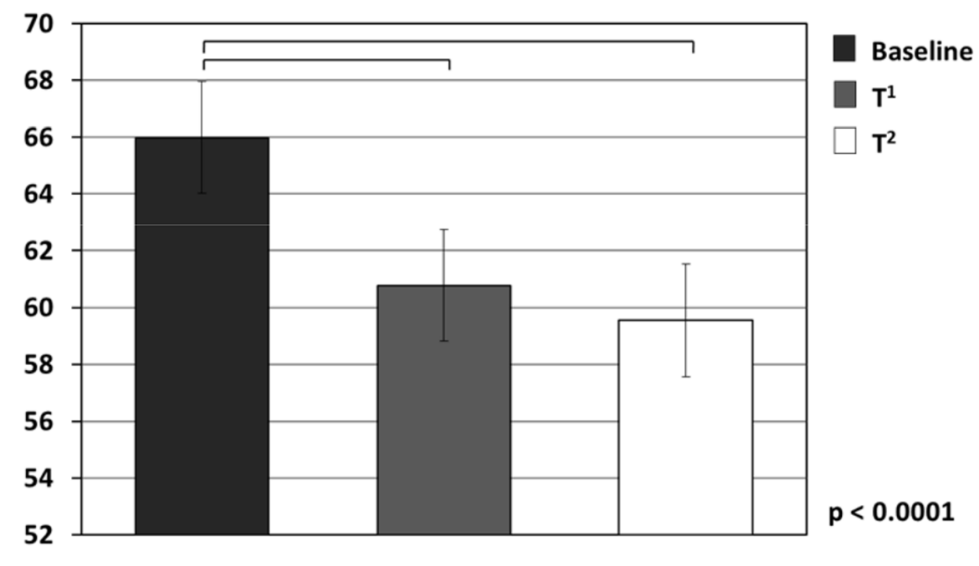

C) Migraine-specific quality-of-life questionnaire

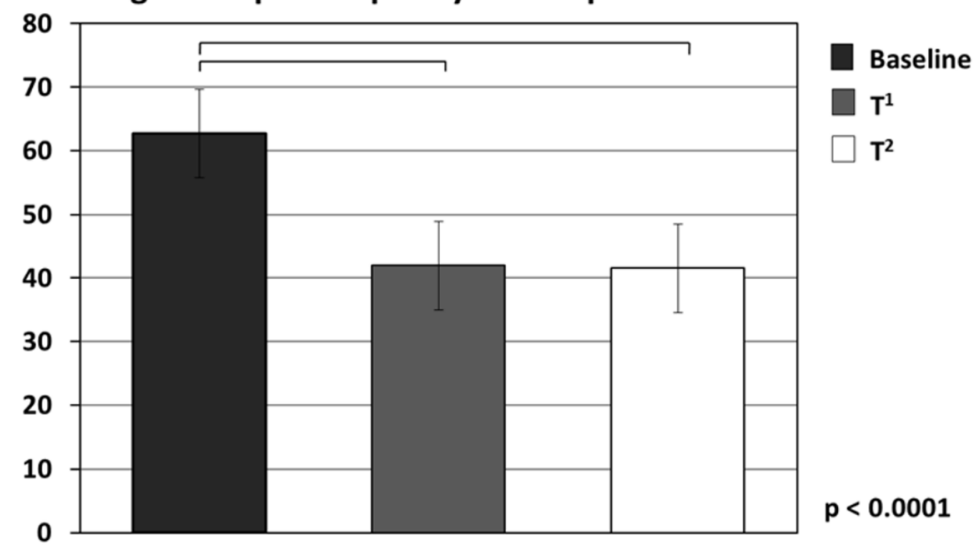

Fig. 3 Migraine-related disability and impact on daily living scores at baseline $\left(T^{0}\right)$, and at the end of the third $\left(T^{1}\right)$ and of the sixth month $\left(T^{2}\right)$ of erenumab administration. HIT: headache impact test; MIDAS: migraine-related disability

reduction in the mean number of migraine days per month was reached by $43.3 \%$ of patients in the $70-\mathrm{mg}$ erenumab group and $50.0 \%$ of patients in the $140-\mathrm{mg}$ erenumab group, as compared with $26.6 \%$ in the placebo group. The efficacy and the safety of monthly erenumab administration have also been observed in the LIBERTY 


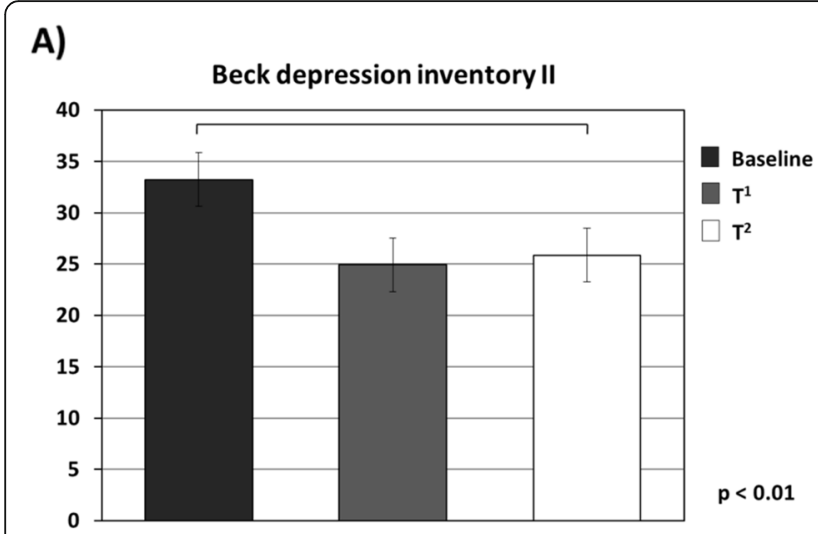

\section{B)}
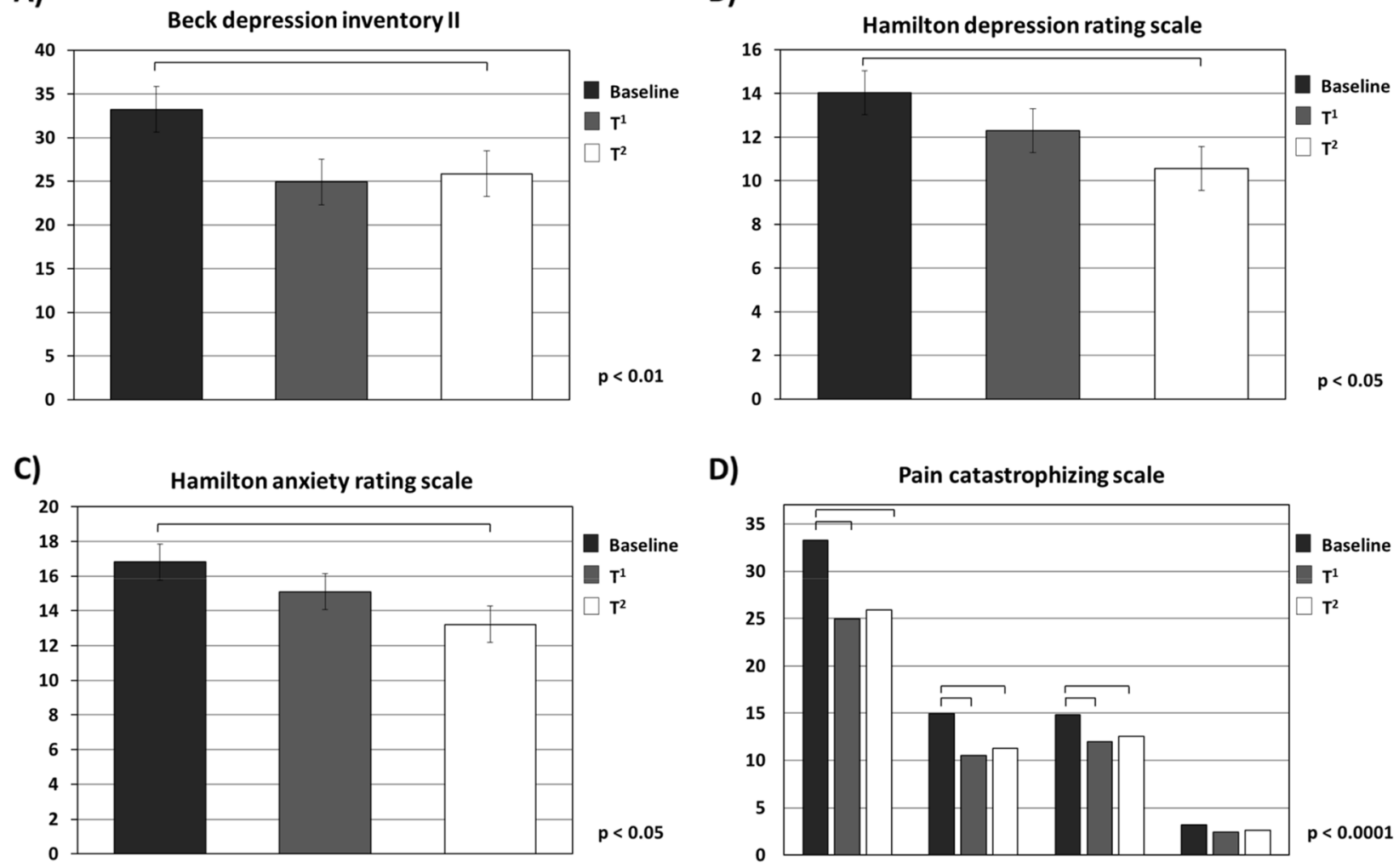

D)

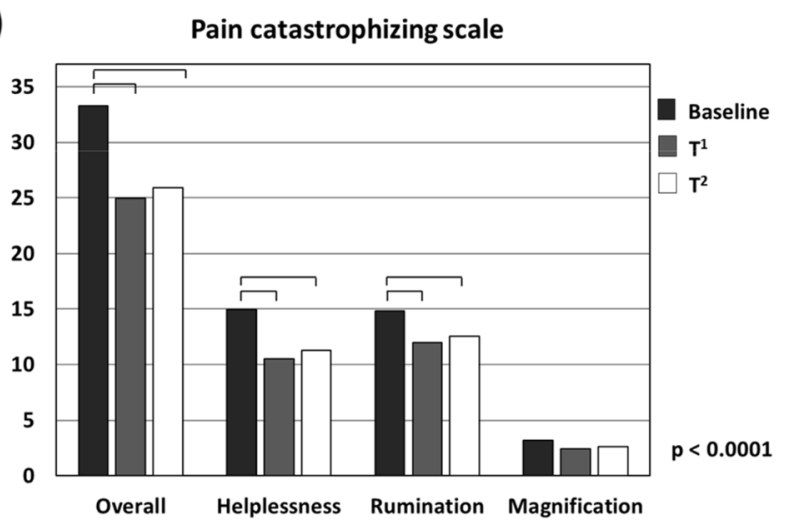

Fig. 4 Depressive and anxiety factors and pain catastrophizing scores at baseline $\left(T^{0}\right)$, and at the end of the third $\left(T^{1}\right)$ and of the sixth month $\left(T^{2}\right)$ of erenumab administration

study, in a group of episodic migraine patients with failure of two-to-four previous preventive treatments, showing, after the third monthly erenumab administration, at least $50 \%$ of reduction in monthly migraine days in the $30 \%$ of patients compared with $14 \%$ in the placebo group [48]. Altogether, a number of randomized trials have documented the efficacy and safety of erenumab in episodic migraine patients with previous preventive treatment failures and in chronic migraine patients, the latter regardless of previous therapeutic strategies [17, 48, 49].

More recently, data from several real-life studies have confirmed the efficacy and tolerability of erenumab in the treatment of migraine patients with previous preventive failures. Specifically, in a real-life Italian observational study in a cohort of 89 patients with episodic or chronic migraine and at least 2 previous preventive treatment failures, $69.7 \%$ of patients had $\mathrm{a} \geq 50 \%$ improvement in monthly migraine days at or before the third dose of erenumab [19]. Moreover, a German analysis of real-world data from 139 chronic migraine patients who had previously failed both $\geq 5$ previous oral preventive treatments and onabotulinumtoxin A showed a $>30 \%$ improvement in monthly headache days in over $50 \%$ of patients after receiving at $\geq 1$ injection of erenumab (Table 4) [20].
However, no data have been produced prospectively regarding chronic migraine patients, with or without medication overuse, who have previously failed preventive treatments. This is probably the most challenging patient population to deal with in clinical practice. Indeed, to date, only data from a sub-analysis are available in chronic migraine patients who had failed prior preventive treatments, showing reductions in monthly headache days of 2.5 , for monthly erenumab $70 \mathrm{mg}$ administration, and 3.3 for monthly erenumab $140 \mathrm{mg}$ administration in patients with $\geq 1$ prior failed medication categories, and of 2.7 and 4.3 respectively for monthly administration of erenumab $70 \mathrm{mg}$ and $140 \mathrm{mg}$ in patients with $\geq 2$ prior failed medications [52]. Nevertheless, the above-mentioned erenumab trials did not extensively investigate the impact of erenumab on deeper and overlooked aspects of the migraine burden, such as quality of life, comorbid depressive and anxiety conditions, and sleep quality in patients with chronic migraine.

In the present study, we demonstrated the efficacy and safety of erenumab in a group of 70 chronic migraine patients, with documented failure to at least four migraine preventive medication classes, over a period of 6 

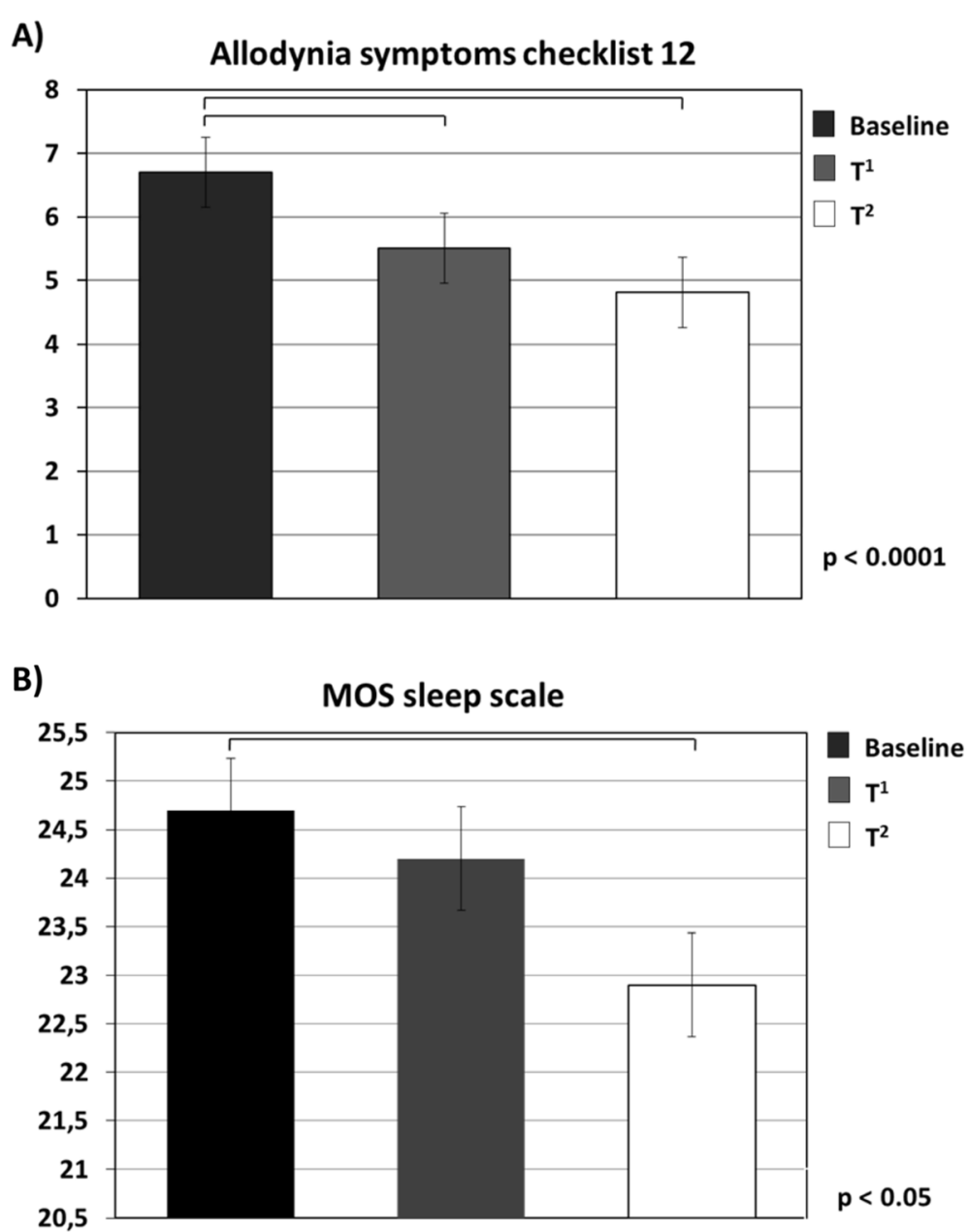

Fig. 5 Allodynia Symptom Checklist-12 (ASC-12) scores and Medical Outcomes Study (MOS) sleep scale scores at baseline $\left(T^{0}\right)$, and at the end of the third $\left(\mathrm{T}^{1}\right)$ and of the sixth month $\left(\mathrm{T}^{2}\right)$ of erenumab administration

months. More specifically, after the third administration of monthly erenumab $70 \mathrm{mg}$ s.c., $70 \%$ of patients were considered "responders" (e.g., $\geq 30 \%$ reduction of headache days/month) and continued with monthly erenumab $70 \mathrm{mg}$ s.c., whereas the remaining $30 \%$ were considered "non-responders" (e.g., <30\% reduction of headache days/month) and therefore switched to monthly erenumab $140 \mathrm{mg}$ s.c. Among the latter, 29\% were considered to have become "responders" after the following three administrations of monthly erenumab $140 \mathrm{mg}$ s.c. After the third administration of monthly erenumab $70 \mathrm{mg}$ s.c. $53 \%$ and $18 \%$ of patients reported respectively $\mathrm{a} \geq 50 \%$ or $\mathrm{a} \geq 75 \%$ reduction in headache days per month. After the sixth administration of monthly erenumab (70 mg s.c. or $140 \mathrm{mg}$ s.c.), $70 \%$ and $26 \%$ of patients reported respectively a $\geq 50 \%$ or a $\geq 75 \%$ reduction in the monthly number of headache days compared to baseline.

Although published randomized trials have not shown statistically significant dose-related differences in clinical response between 70 or $140 \mathrm{mg}$ doses of erenumab, our data are in line with sub-analysis of previous randomized trials showing slight clinical advantages of the higher dose in migraine patients with previous preventive treatment failures. We cannot exclude that the higher dosage of erenumab could be necessary to achieve an adequate control of migraine symptoms in patients with a more severe clinical phenotype characterized by failure of previous treatments [54]. Furthermore, to better characterize the benefits of erenumab treatment and to achieve a more comprehensive view of patient experience, beyond the rude counts of headache days or migraine pain intensity scores, several patient-reported outcomes (PROs) were considered. Among these, wellvalidated questionnaires were employed to evaluate migraine severity, by the HIT-6, to determine how often headaches interfered with activities or caused distress, the MIDAS to assess the number of productive days lost, and the MSQ to measure the effect of migraine on daily functioning. In line with evidence from the literature, a 
Table 4 Synoptic review of randomized controlled trials and real-life experiences using erenumab as a preventive treatment for migraine

\begin{tabular}{|c|c|c|c|c|c|}
\hline Study & Study design & $\begin{array}{l}\text { Type of } \\
\text { patients }\end{array}$ & $\begin{array}{l}\text { Preventive } \\
\text { medications }\end{array}$ & $\begin{array}{l}\text { Previous treatment } \\
\text { failures }\end{array}$ & $\begin{array}{l}\text { Main findings for erenumab compared with } \\
\text { controls }\end{array}$ \\
\hline $\begin{array}{l}\text { Tepper et al. } \\
\text { (2017) NCT02 } \\
066415 \text { [49] }\end{array}$ & $\begin{array}{l}\text { Randomized, double-blind, } \\
\text { placebo-controlled, phase } 2 \\
\text { trial }\end{array}$ & $\begin{array}{l}\text { Chronic } \\
\text { migraine }\end{array}$ & $\begin{array}{l}\text { Not } \\
\text { allowed }\end{array}$ & $\leq 3$ (no response) & $\begin{array}{l}\text { MMD reduced by } 6.6 \text { days vs. } 4.2 \text { days with placebo } \\
40 \% \text { vs. } 41 \% \text { in the erenumab } 70 \mathrm{mg} \text { vs. } 140 \mathrm{mg} \\
\text { groups achieved } a \geq 50 \% \text { reduction }\end{array}$ \\
\hline $\begin{array}{l}\text { Dodick et al. } \\
\text { (2018) } \\
\text { ARISE [50] }\end{array}$ & $\begin{array}{l}\text { Randomized, double-blind, } \\
\text { placebo-controlled, phase } 3 \\
\text { study }\end{array}$ & $\begin{array}{l}\text { Episodic } \\
\text { migraine }\end{array}$ & Allowed & $<2$ (no response) & $\begin{array}{l}\text { MMD reduced by } 2.9 \text { days vs. } 1.8 \text { days with placebo } \\
39.7 \% \text { of erenumab recipients achieved } \geq 50 \% \\
\text { reduction }\end{array}$ \\
\hline $\begin{array}{l}\text { Goadsby } \\
\text { et al. } 2017 \\
\text { STRIVE [51] }\end{array}$ & $\begin{array}{l}\text { Randomized, double-blind, } \\
\text { placebo-controlled, phase } 3 \\
\text { study }\end{array}$ & $\begin{array}{l}\text { Episodic } \\
\text { migraine }\end{array}$ & $\begin{array}{l}\text { Allowed }(< \\
\text { 2) }\end{array}$ & $\leq 2$ (no response) & $\begin{array}{l}\text { MMD reduced by } 3.2 \text { vs. days in the erenumab } 70 \\
\text { mg vs. } 140 \mathrm{mg} \text { group, and by } 1.8 \text { days with } \\
\text { placebo. } 43.3 \%, 50.0 \% \text {, and } 26.6 \% \text {, respectively, } \\
\text { achieved } a \geq 50 \% \text { reduction in MMD }\end{array}$ \\
\hline $\begin{array}{l}\text { Ashina et al. } \\
\text { (2018) [52] }\end{array}$ & $\begin{array}{l}\text { Randomized, double-blind, } \\
\text { placebo-controlled study } \\
\text { with subgroup analyses }\end{array}$ & $\begin{array}{l}\text { Chronic } \\
\text { migraine }\end{array}$ & $\begin{array}{l}\text { Not } \\
\text { allowed }\end{array}$ & $0, \geq 1, \geq 2$ (no response) & $\begin{array}{l}\text { Reduction in MMD vs. placebo for erenumab } 70 \\
\text { mg vs. } 140 \text { mg: No prior treatment failure, } 2.2 \text { vs. } \\
0.5 \text { days; } \geq 1 \text { prior failed medication category } \\
\text { subgroup, } 2.5 \text { vs. } 3.3 \text { days; } \geq 2 \text { prior failed } \\
\text { medication categories, } 2.7 \text { vs. } 4.3 \text { days }\end{array}$ \\
\hline $\begin{array}{l}\text { Reuter et al. } \\
\text { (2018) } \\
\text { LIBERTY [48] }\end{array}$ & $\begin{array}{l}\text { Randomized, double-blind, } \\
\text { placebo-controlled, phase } \\
\text { 3b study }\end{array}$ & $\begin{array}{l}\text { Episodic } \\
\text { migraine }\end{array}$ & $\begin{array}{l}\text { Not } \\
\text { allowed }\end{array}$ & $\begin{array}{l}\text { Failure of } 2-4 \text { prior } \\
\text { preventive treatments }\end{array}$ & MMD reduced by $\geq 50 \%$ in $30 \%$ of patients \\
\hline $\begin{array}{l}\text { Barbanti et al. } \\
\text { (2019) [18] }\end{array}$ & Real-life data & $\begin{array}{l}\text { Episodic } \\
\text { and } \\
\text { chronic } \\
\text { migraine }\end{array}$ & Allowed & $\begin{array}{l}\text { Failure of } 4-6 \text { prior } \\
\text { preventive treatments }\end{array}$ & $\begin{array}{l}\geq 50 \% \text { reduction of MMD at weeks } 4 \text { and } 8, \\
\text { respectively, in } 68.2 \% \text { and } 87.5 \% \text { of chronic patients } \\
\text { and } 50 \% \text { and } 100 \% \text { of episodic patients }\end{array}$ \\
\hline $\begin{array}{l}\text { Ornello et al. } \\
\text { (2020) [19] }\end{array}$ & Real-life data & $\begin{array}{l}\text { Episodic } \\
\text { and } \\
\text { chronic } \\
\text { migraine }\end{array}$ & Allowed & $\begin{array}{l}\text { Failure of } \geq 2 \text { prior } \\
\text { preventive treatments }\end{array}$ & $\begin{array}{l}\text { MMD reduced from a mean of } 19 \text { days to } 4 \text { days. } \\
\text { MMD reduced by } \geq 50 \% \text { in } 70 \% \text { of patients }\end{array}$ \\
\hline $\begin{array}{l}\text { Raffaelli et al. } \\
\text { (2020) [20] }\end{array}$ & Retrospective real-life & $\begin{array}{l}\text { Chronic } \\
\text { migraine }\end{array}$ & $\begin{array}{l}\text { Not } \\
\text { specified }\end{array}$ & $\begin{array}{l}\text { Failure of } 5 \text { prior } \\
\text { preventive treatments } \\
\text { plus } \\
\text { onabotulinumtoxinA }\end{array}$ & $\begin{array}{l}\text { MHD reduction of } 3.7 \text { days after the first treatment } \\
\text { and } 4.7 \text { days after } 3 \text { treatment cycles }\end{array}$ \\
\hline $\begin{array}{l}\text { Robbins et al. } \\
\text { (2020) [53] }\end{array}$ & Retrospective real-life & $\begin{array}{l}\text { Chronic } \\
\text { migraine }\end{array}$ & Allowed & $\begin{array}{l}\text { Failure of } \geq 3 \text { prior } \\
\text { preventive treatments }\end{array}$ & MMD reduced by $\geq 30 \%$ in $43 \%$ of patients \\
\hline
\end{tabular}

$M H D$ monthly headache days, $M M D$ monthly migraine days, vs. versus

high impact and severe disability, as well as substantial impairments in migraine-specific quality of life, were found in our chronic migraine population. After the third and, even more, after the sixth monthly erenumab administration, a statistically significant improvement across this broad set of PROs became evident. Interestingly, a statistically significant reduction in migraine impact (e.g., by HIT-6) was detected in the 30 days following the first erenumab administration and sustained through the 6-months evaluation.

It is of note that migraine has been widely shown to be associated with depression and anxiety [55]. Although the possibility of common pathophysiological mechanisms is still a matter of debate [56,57], it is well-known that depressive and anxious conditions make migraine treatment more challenging and are associated with negative outcomes, including increased rates of chronic migraine onset or progression, reduced quality of life and increased overall disease burden [58]. In our population of chronic migraine patients, $75 \%$ showed mild depression comorbidity (according to the HDRS or the self-administrated BDI-II), and 58\% reported moderate anxiety comorbidity (according to the HARS). A statistically significant improvement in HDRS and selfadministered BDI-II scores, achieving values consistent with the absence of depressive contents, and in HARS scores, consistent with the absence of anxiety, were found only after the sixth administration of monthly erenumab, suggesting that longer times are required to improve psychiatric comorbidities in these patients. Interestingly, a remission in depressive symptoms (defined by final BDI-II score $<9$ ) was observed in 23 patients after the sixth administration of monthly erenumab.

Beyond depressive and anxiety factors, migraine patients employ maladaptive pain coping strategies, such as the so-called "pain catastrophizing", consisting of negative cognitive and affective behavior in response to anticipated or actual pain. In particular, patients who "catastrophize" can experience difficulty in inhibiting 
thoughts about pain (rumination), exaggerate and worry about the negative consequences of pain (magnification), and believe there is nothing they can do to alleviate the pain (helplessness) [59]. It has been widely demonstrated that pain catastrophizing is associated with increased pain experience and reporting, pain behavior, decreased quality of life, and greater use of healthcare services and longer hospital stays $[60,61]$. Among patients with migraine, "catastrophizing" habits are associated with more frequent migraine attacks and chronic migraine, poorer treatment response, increased medical consultation, impaired functioning and reduced health-related quality of life [62]. In this context, the majority of our patients showed PCS scores witnessing negative orientation toward actual or anticipated pain experience. A significant reduction in PCS scores (e.g., mean value below the cutoff value for an aberrant approach to the pain experience) was found after the third monthly erenumab administration, with a better response related to pain rumination and helplessness sub-domains.

Regarding the relationship between sleep and migraine, although the increased incidence and prevalence of sleep disorders in migraine patients is undeniable [63, 64], discussions remain. Insomnia is the most common sleep complaint among migraine patients since it has been observed in $40 \%$ of episodic migraine patients and almost $70 \%$ of chronic migraine patients, half of which also reporting snoring during sleep [65]. It has been suggested that sleep disorders may predispose individuals to migraine attacks and play a role in migraine chronification [66] and, on the other hand, management of insomnia may reverse chronic in episodic migraine or prevent migraine chronification [67]. Therefore, as sleep disorders could be involved in the onset and resolution of symptoms, they should be carefully considered when discussing migraine management. In the present study, sleep disorders were assessed using the MOS sleep scale, a self-administered scale able to assess 6 different sleep disturbances (difficulty falling asleep and maintaining sleep, daytime sleepiness, respiratory disorders, presence of rhonchopathy, amount of sleep). Global improvement in sleep patterns was demonstrated by a statistically significant reduction of sleep problem index after the sixth monthly erenumab administration.

About two-thirds of migraine patients report cutaneous allodynia, the perception of pain induced by trivial stimuli to normal skin, during or between headache episodes. This is known to represent a risk factor for migraine chronification [68, 69]. In our patient sample, $80 \%$ reported ictal cutaneous allodynia at baseline. A statistically significant reduction in ASC-12 values was observed after the third and sixth monthly erenumab administrations, while after the sixth erenumab administration, 13 patients converted to non-allodynia.
Non-pain symptoms, frequently reported by patients with migraine during attacks, could strongly contribute to migraine-related disability [70, 71]. Among these, aside from the "core symptoms" associated with sensory hypersensitivity and neuro-vegetative involvement, cognitive dysfunctions, mainly involving executive and language domains, are often experienced by patients during migraine attacks [72]. Interestingly, in our observation, erenumab did not result in a reduction in the cognitive symptoms associated with migraine attacks, either at the third or sixth monthly erenumab administrations. We speculate that, in acting at the peripheral level of the trigemino-vascular system, longer erenumab treatments could be necessary to re-modulate, even indirectly, the central dysfunctions subtending migraine-related cognitive symptoms.

Finally, our secondary analysis showed that monthly erenumab administration was effective even in a subgroup of patients previously unsuccessfully treated with onabotulinumtoxinA [73].

Multivariate regression analysis illustrated the negative predictive role of disease duration on the response to erenumab treatment. That is, the shorter the disease duration, the better the therapeutic response to erenumab. This finding has also been shown for onabotulinumtoxinA, which is likewise known to work on the CGRP pathway, and could support the early use of erenumab, particularly considering the high efficacy and very good safety profile of erenumab $[74,75]$.

One of the leading causes of low adherence to preventive migraine treatment is poor tolerability, characterized by systemic and often disabling AEs, such as reduced attention, somnolence, tremor, dizziness, fatigue, depression, loss of appetite, weight gain, hair loss and changes in libido [76]. These side effects were not observed during monthly administrations of either dose of erenumab in the course of 6 months' observation.

In our study, there were no patient-reported serious AEs or decisions to discontinue treatment due to poor tolerability, although a percentage of migraine patients, higher than those observed by previous erenumab clinical trials, reported constipation, fatigue, and nausea. On the other hand, we cannot exclude that the higher incidence of the AEs reported in our study may reflect an interaction between erenumab and concomitant therapies.

\section{Conclusion}

Our data from the Italian real-world setting support monthly erenumab 70 or $140 \mathrm{mg}$ s.c. as an effective preventive treatment able to reduce headache frequency and severity in a significant percentage of chronic migraine patients experiencing previous unsuccessful preventive treatments. In addition, erenumab showed a 
significant effect on migraine-related disability and migraine impact on daily living, as well as on both depressive and anxiety symptoms, health-related quality of life, quality of sleep and pain catastrophizing.

This study has many strengths. In particular, although open-label studies with long-term follow-up may be subject to unintentional bias, such as low persistency rates and concomitant medication changes, we observed a persistency of $100 \%$ in the absence of changes in preventive medications.

On the other hand, this study is not without limitations. First of all, being a non-randomized open-label study, there was no placebo or active comparator arm. However, an open-label design is informative when the efficacy and safety profile of treatment is established, as it is with erenumab for chronic migraine.

In conclusion, erenumab is not only highly effective but also able to meaningfully alleviate the burden of migraine, with a very low percentage of mild side-effects.

\section{Abbreviations}

AE: Adverse event; ASC: Allodynia Symptom Checklist; BDI-II: Beck Depression Inventory-II; CGRP: Calcitonin gene-related peptide; HARS: Hamilton Anxiety Rating Scale; HDRS: Hamilton Depression Rating Scale; HIT: Headache impact test; mAb: Monoclonal antibody; MIDAS: Migraine-related disability; MIGSCOG: MIGraine attacks-Subjective COGnitive impairments scale; MOS: Medical Outcomes Study; MSQ: Migraine-specific quality-of-life questionnaire; NRS: Numerical rating scale; PCS: Pain Catastrophizing Scale; QoL: Quality of life; STROBE: Strengthening the Reporting of Observational Studies in Epidemiology

\section{Acknowledgments}

We thank Ray Hill, an independent medical writer, who provided medical writing support on behalf of Health Publishing \& Services Srl. This unconditional support was funded by Novartis Farma.

\section{Authors' contributions}

Prof Russo: experimental design, image data analysis, results interpretation, manuscript drafting and revision; Dr. Silvestro: literature review, experimental design, results interpretation, manuscript revision; Dr. Fabrizio Scotto di Clemente: image data analysis and results interpretation; Dr. Trojsi: image data analysis and results interpretation; Dr. Bisecco: literature review and results interpretation; Prof Bonavita: experimental design, manuscript revision Prof Tessitore: experimental design, image data analysis, results interpretation, manuscript revision; Prof Tedeschi: experimental design, results interpretation, manuscript revision. The authors read and approved the final manuscript.

\section{Funding}

This research received no specific grant from any funding agency in the public, commercial, or not-for-profit sectors.

\section{Availability of data and materials}

The data sets analyzed during the current study are available from the corresponding author on reasonable request.

\section{Ethics approval and consent to participate}

The study protocol was reviewed and approved by the Ethical Committee of the University of Campania "Luigi Vanvitelli". The study was conducted according to the ethical principles of the Declaration of Helsinki. Informed consent to participate in the study was obtained from all patients.

\section{Consent for publication}

Not applicable.

\section{Competing interests}

Professor Russo has received speaker honoraria from Allergan, Novartis, Lilly and Teva and serves as an associate editor of Frontiers in Neurology (Headache Medicine and Facial Pain session). Professor Tessitore has received speaker honoraria from Novartis, Schwarz Pharma/UCB, Lundbeck, Abbvie and Glaxo. Professor Tedeschi has received speaker honoraria from SanofiAventis, Merck Serono, Bayer Schering Pharma, Novartis, Biogen-Dompe' AG; has received funding for travel from Bayer Schering Pharma, Biogen-Dompe' AG, Merck Serono, Novartis and Sanofi Aventis; and serves as an associate editor of Neurological Sciences. The other authors have nothing to declare.

\section{Author details}

${ }^{1}$ Department of Medical, Surgical, Neurological, Metabolic and Aging Sciences, Headache Center, University of Campania "Luigi Vanvitelli", Piazza Miraglia 2 - I, 80138 Naples, Italy. ${ }^{2}$ Institute for Diagnosis and Care, 'Hermitage-Capodimonte', Naples, Italy.

Received: 3 April 2020 Accepted: 1 June 2020

Published online: 09 June 2020

\section{References}

1. Headache Classification Committee of the International Headache Society (IHS) (2018) The International Classification of Headache Disorders, 3rd edition. Cephalalgia 38(1):1-211.

2. Russo A, Silvestro M, Tedeschi G, Tessitore (2017) A physiopathology of migraine: what have we learned from functional imaging? Curr Neurol Neurosci Rep 17:95

3. Ford JH, Jackson J, Milligan G, Cotton S, Ahl J, Aurora SK (2017) A real-world analysis of migraine: a cross-sectional study of disease burden and treatment patterns. Headache. 57:1532-1544

4. Silberstein SD, Holland S, Freitag F, Dodick DW, Argoff C, Ashman E et al (2012) Evidence-based guideline update: pharmacologic treatment for episodic migraine prevention in adults: report of the quality standards Subcommittee of the American Academy of neurology and the American headache society. Neurology. 78:1337-1345

5. Goadsby PJ, Sprenger T (2010) Current practice and future directions in the prevention and acute management of migraine. Lancet Neurol 9:285-298

6. Lipton RB, Silberstein SD (2015) Episodic and chronic migraine headache: breaking down barriers to optimal treatment and prevention. Headache 55(Suppl 2):103-126.

7. Chan C, Goadsby PJ (2019) Recent advances in pharmacotherapy for episodic migraine. CNS Drugs. 33:1053-1071

8. Dodick DW (2019) CGRP ligand and receptor monoclonal antibodies for migraine prevention: evidence review and clinical implications. Cephalalgia. 39:445-458

9. Maasumi K, Michael RL, Rapoport AM (2018) CGRP and migraine: the role of blocking calcitonin gene-related peptide ligand and receptor in the management of migraine. Drugs. 78:913-928

10. Haanes KA, Edvinsson L (2019) Pathophysiological mechanisms in migraine and the identification of new therapeutic targets. CNS Drugs 33:525-537

11. McCafferty EH, Lyseng-Williamson KA (2019) Erenumab in the prophylaxis of migraine: a profile of its use. Drugs Ther Perspect 35:13-20

12. Ong JJY, Wei DY, Goadsby PJ (2018) Recent advances in pharmacotherapy for migraine prevention: from pathophysiology to new drugs. Drugs. 78:411-437

13. Mitsikostas DD, Reuter U (2017) Calcitonin gene-related peptide monoclonal antibodies for migraine prevention: comparisons across randomized controlled studies. Curr Opin Neurol 30:272-280

14. Raffaelli B, Reuter U (2018) The biology of monoclonal antibodies: focus on calcitonin gene-related peptide for prophylactic migraine therapy. Neurotherapeutics. 15:324-335

15. European Medicines Agency (EMA). 2018. Aimovig (erenumab): summary of product characteristics. Available from: https://wwwemaeuropaeu/ Accessed November 2019

16. U.S. Food and Drug Administration (FDA) (2018) AIMOVIG ${ }^{\mathrm{TM}}$ (erenumabaooe) injection, for subcutaneous use. Highlights of Prescribing Information. https://www.accessdata.fda.gov/. Accessed 28 November 2019

17. Lattanzi S, Brigo F, Trinka E, Vernieri F, Corradetti T, Dobran M et al (2019) Erenumab for preventive treatment of migraine: a systematic review and meta-analysis of efficacy and safety. Drugs. 79:417-431 
18. Barbanti P, Aurilia C, Egeo G, Fofi L (2019) Erenumab: from scientific evidence to clinical practice-the first Italian real-life data. Neurol Sci 40:177179

19. Ornello R, Casalena A, Frattale I, Gabriele A, Affaitati G, Giamberardino MA et al (2020) Real-life data on the efficacy and safety of erenumab in the Abruzzo region, Central Italy. J Headache Pain. 21:32

20. Raffaelli B, Kalantzis R, Mecklenburg J, Overeem LH, Neeb L, Gendolla A et al (2020) Erenumab in chronic migraine patients who previously failed five first-line oral prophylactics and onabotulinumtoxinA: a dual center retrospective observational study. Front Neurol 11:417

21. Lambru G, Hill B, Murphy M, Andreou AP (2019) Erenumab for the treatment of refractory chronic migraine: a UK prospective real world experience [abstract IHC-PO-390]. Cephalalgia. 39:255-256

22. Jenkins B, Cheng S, Limberg N, Hutton E (2019) Will refractory migraine patients in the real world respond to Erenumab? [abstract IHC-PO-405]. Cephalalgia. 39:265-266

23. Steiner TJ, Martelletti P (2007) Aids for management of common headache disorders in primary care. J Headache Pain. 8:S2-S47

24. Silberstein S, Tfelt-Hansen P, Dodick DW, Limmroth V, Lipton RB, Pascual J et al (2008) Guidelines for controlled trials of prophylactic treatment of chronic migraine in adults. Cephalalgia. 28:484-495

25. Lipton R, Desai P, Sapra S, Buse D, Fanning K, Reed M (2017) How much change in headache-related disability is clinically meaningful? Estimating minimally important difference (MID) or change in MIDAS using data from the AMPP Study. Headache 57:165

26. Stewart WF, Lipton RB, Dowson AJ, Sawyer J (2001) Development and testing of the migraine disability assessment (MIDAS) questionnaire to assess headache-related disability. Neurology. 56:S20-S28

27. Coeytaux RR, Kaufman JS, Chao R, Mann JD, Devellis RF (2006) Four methods of estimating the minimal important difference score were compared to establish a clinically significant change in headache impact test. J Clin Epidemiol 59:374-380

28. Kosinski M, Bayliss MS, Bjorner JB, Ware JE Jr, Garber WH, Batenhorst A et al (2003) A six-item short-form survey for measuring headache impact: the HIT-6. Qual Life Res 12:963-974

29. Yang M, Rendas-Baum R, Varon SF, Kosinski M (2011) Validation of the headache impact test (HIT-6) across episodic and chronic migraine. Cephalalgia. 31:357-367

30. Worboys M (2013) The Hamilton Rating Scale for Depression: The making of a "gold standard" and the unmaking of a chronic illness, 1960-1980. Chronic IIIn 9:202-219

31. Maier W, Buller R, Philipp M, Heuser I (1988) The Hamilton anxiety scale: reliability, validity and sensitivity to change in anxiety and depressive disorders. J Affect Disord 14:61-68

32. Stewart A, Ware JE, Brook RH, Davies AR (1978) Conceptualization and measurement of health for adults in the health insurance study: Vol. II, physical health in terms of functioning. Rand Corporation, Santa Monica, CA, USA

33. Cole JC, Lin P, Rupnow MF (2009) Minimal important differences in the migraine-specific quality of life questionnaire (MSQ) version. Cephalalgia. 29: 1180-1187

34. Jhingran P, Osterhaus JT, Miller DW, Lee JT, Kirchdoerfer L (1998) Development and validation of the migraine-specific quality of life questionnaire. Headache. 38:295-302

35. Sullivan MJ, Bishop SR, Pivik J (1995) The pain catastrophizing scale: development and validation. Psychol Assess 7:524-532

36. Melhado EM, Thiers Rister HL, Galego DR, de Oliveira AB, Buttarello IA, Belucio IS et al (2020) Allodynia in menstrually related migraine: score assessment by Allodynia symptom checklist (ASC-12). Headache. 60:162-170

37. Gil-Gouveia R, Oliveira AG, Martins IP (2011) A subjective cognitive impairment scale for migraine attacks. The MIG-SCOG: development and validation. Cephalalgia. 31:984-991

38. von Elm E, Altman DG, Egger M, Pocock SJ, Gotzsche PC, Vandenbroucke JP et al (2007) The strengthening the reporting of observational studies in epidemiology (STROBE) statement: guidelines for reporting observational studies. Lancet. 370:1453-1457

39. Ashina M, Kudrow D, Reuter U, Dolezil D, Silberstein S, Tepper SJ et al (2019) Long-term tolerability and nonvascular safety of erenumab, a novel calcitonin gene-related peptide receptor antagonist for prevention of migraine: a pooled analysis of four placebo-controlled trials with long-term extensions. Cephalalgia. 39:1798-1808
40. Buse DC, Fanning KM, Reed ML, Murray S, Dumas PK, Adams AM et al (2019) Life with migraine: effects on relationships, career, and finances from the chronic migraine epidemiology and outcomes (CaMEO) study. Headache. 59:1286-1299

41. GBD 2017 Disease and Injury Incidence and Prevalence Collaborators Global, regional, and national incidence, prevalence, and years lived with disability for 354 diseases and injuries for 195 countries and territories, 1990-2017: A systematic analysis for the Global Burden of Disease Study 2017. Lancet. 2018:392:1789-1858

42. Katsarava Z, Mania M, Lampl C, Herberhold J, Steiner TJ (2018) Poor medical care for people with migraine in Europe - evidence from the Eurolight study. J Headache Pain. 19:10

43. Ceriani CEJ, Wilhour DA, Silberstein SD (2019) Novel medications for the treatment of migraine. Headache. 59:1597-1608

44. Scuteri D, Adornetto A, Rombola L, Naturale MD, Morrone LA, Bagetta G et al (2019) New trends in migraine pharmacology: targeting calcitonin gene-related peptide (CGRP) with monoclonal antibodies. Front Pharmacol 10:363

45. Ashina M, Goadsby PJ, Reuter U, Silberstein S, Dodick D, Rippon GA et al (2019) Long-term safety and tolerability of erenumab: three-plus year results from a five-year open-label extension study in episodic migraine. Cephalalgia. 39:1455-1464

46. Goadsby PJ, Paemeleire K, Broessner G, Brandes J, Klatt J, Zhang F et al (2019) Efficacy and safety of erenumab (AMG334) in episodic migraine patients with prior preventive treatment failure: a subgroup analysis of a randomized, double-blind, placebo-controlled study. Cephalalgia. 39:817826

47. Lipton RB, Tepper SJ, Reuter U, Silberstein S, Stewart WF, Nilsen J et al (2019) Erenumab in chronic migraine: patient-reported outcomes in a randomized double-blind study. Neurology. 92:e2250-e2260

48. Reuter U, Goadsby PJ, Lanteri-Minet M, Wen S, Hours-Zesiger P, Ferrari MD et al (2018) Efficacy and tolerability of erenumab in patients with episodic migraine in whom two-to-four previous preventive treatments were unsuccessful: a randomised, double-blind, placebo-controlled, phase $3 \mathrm{~b}$ study. Lancet. 392:2280-2287

49. Tepper S, Ashina M, Reuter U, Brandes JL, Dolezil D, Silberstein S et al (2017) Safety and efficacy of erenumab for preventive treatment of chronic migraine: a randomised, double-blind, placebo-controlled phase 2 trial. Lancet Neurol 16:425-434

50. Dodick DW, Ashina M, Brandes JL, Kudrow D, Lanteri-Minet M, Osipova V et al (2018) ARISE: a phase 3 randomized trial of erenumab for episodic migraine. Cephalalgia. 38:1026-1037

51. Goadsby PJ, Reuter U, Hallstrom Y, Broessner G, Bonner JH, Zhang F et al (2017) A controlled trial of erenumab for episodic migraine. N Engl J Med 377:2123-2132

52. Ashina M, Tepper S, Brandes JL, Reuter U, Boudreau G, Dolezil D et al (2018) Efficacy and safety of erenumab (AMG334) in chronic migraine patients with prior preventive treatment failure: a subgroup analysis of a randomized, double-blind, placebo-controlled study. Cephalalgia. 38:16111621

53. Robbins $L$ (2020) Special report: CGRP monoclonal antibodies for chronic migraine. Practical Pain Management 19:45-52

54. Ornello R, Tiseo C, Frattale I, Perrotta G, Marini C, Pistoia F et al (2019) The appropriate dosing of erenumab for migraine prevention after multiple preventive treatment failures: a critical appraisal. J Headache Pain. 20:99

55. Buse DC, Manack A, Serrano D, Turkel C, Lipton RB (2010) Sociodemographic and comorbidity profiles of chronic migraine and episodic migraine sufferers. J Neurol Neurosurg Psychiatry 81:428-432

56. Breslau N, Lipton RB, Stewart WF, Schultz LR, Welch KM (2003) Comorbidity of migraine and depression: investigating potential etiology and prognosis. Neurology. 60:1308-1312

57. Yang Y, Zhao H, Heath AC, Madden PA, Martin NG, Nyholt DR (2016) Shared genetic factors underlie migraine and depression. Twin Res Hum Genet 19: 341-350

58. Ashina S, Serrano D, Lipton RB, Maizels M, Manack AN, Turkel CC et al (2012) Depression and risk of transformation of episodic to chronic migraine. J Headache Pain 13:615-624

59. Sullivan MJ, Thorn B, Haythornthwaite JA, Keefe F, Martin M, Bradley LA et a (2001) Theoretical perspectives on the relation between catastrophizing and pain. Clin J Pain 17:52-64 
60. Peters ML, Vlaeyen JW, Weber WE (2005) The joint contribution of physical pathology, pain-related fear and catastrophizing to chronic back pain disability. Pain. 113:45-50

61. Severeijns R, Vlaeyen JW, van den Hout MA, Weber WE (2001) Pain catastrophizing predicts pain intensity, disability, and psychological distress independent of the level of physical impairment. Clin J Pain 17:165-172

62. Holroyd KA, Drew JB, Cottrell CK, Romanek KM, Heh V (2007) Impaired functioning and quality of life in severe migraine: the role of catastrophizing and associated symptoms. Cephalalgia. 27:1156-1165

63. Vgontzas A, Pavlovic JM (2018) Sleep disorders and migraine: review of literature and potential pathophysiology mechanisms. Headache. 58:10301039

64. Kelman L, Rains JC (2005) Headache and sleep: examination of sleep patterns and complaints in a large clinical sample of migraineurs. Headache. 45:904-910

65. Sancisi E, Cevoli S, Vignatelli L, Nicodemo M, Pierangeli G, Zanigni S et al (2010) Increased prevalence of sleep disorders in chronic headache: a casecontrol study. Headache. 50:1464-1472

66. Klenofsky B, Pace A, Natbony LR, Sheikh HU (2019) Episodic migraine comorbidities: avoiding pitfalls and taking therapeutic opportunities. Curr Pain Headache Rep 23:1

67. Yang CP, Wang SJ (2017) Sleep in patients with chronic migraine. Curr Pain Headache Rep 21:39

68. Lipton RB, Fanning KM, Buse DC, Martin VT, Hohaia LB, Adams AM et al (2019) Migraine progression in subgroups of migraine based on comorbidities: results of the CaMEO study. Neurology. 93:e2224-e2236

69. Louter MA, Bosker JE, van Oosterhout WP, van Zwet EW, Zitman FG, Ferrari MD et al (2013) Cutaneous allodynia as a predictor of migraine chronification. Brain. 136:3489-3496

70. Gil-Gouveia R, Oliveira AG, Martins IP (2016) The impact of cognitive symptoms on migraine attack-related disability. Cephalalgia. 36:422-430

71. Russo A, Silvestro M, Garramone F, Tessitore A, Cropano M, Scotto di Clemente $\mathrm{F}$ et al. A subjective cognitive impairments scale for migraine attacks: Validation of the Italian version of the MIG-SCOG. Neurol Sci. 2020

72. Vuralli D, Ayata C (2018) Bolay H cognitive dysfunction and migraine. Headache Pain. 19:109

73. Bendtsen L, Sacco S, Ashina M, Mitsikostas D, Ahmed F, Pozo-Rosich P et al (2018) Guideline on the use of onabotulinumtoxinA in chronic migraine: a consensus statement from the European headache federation. J Headache Pain. 19:91

74. Tassorelli C, Aguggia M, De Tommaso M, Geppetti P, Grazzi L, Pini LA et al (2017) Onabotulinumtoxin a for the management of chronic migraine in current clinical practice: results of a survey of sixty-three Italian headache centers. J Headache Pain. 18:66

75. Kim CC, Bogart MM, Wee SA, Burstein R, Arndt KA, Dover JS (2010) Predicting migraine responsiveness to botulinum toxin type a injections. Arch Dermatol 146:159-163

76. Sarchielli P, Granella F, Prudenzano MP, Pini LA, Guidetti V, Bono G et al (2012) Italian guidelines for primary headaches: 2012 revised version. J Headache Pain. 13(Suppl 2):S31-S70

\section{Publisher's Note}

Springer Nature remains neutral with regard to jurisdictional claims in published maps and institutional affiliations.

\section{Ready to submit your research? Choose BMC and benefit from:}

- fast, convenient online submission

- thorough peer review by experienced researchers in your field

- rapid publication on acceptance

- support for research data, including large and complex data types

- gold Open Access which fosters wider collaboration and increased citations

- maximum visibility for your research: over $100 \mathrm{M}$ website views per year

At BMC, research is always in progress.

Learn more biomedcentral.com/submissions 